\title{
A Study on Mechanical Behaviour of Surface Modified Rice Husk/Polypropylene Composite Using Sodium Hydroxide
}

\author{
Kannan Rassiah ${ }^{1,}$ a and Aidy Ali $^{2, b^{*}}$ \\ ${ }^{1}$ Department of Mechanical Engineering, Politeknik Port Dickson (PPD), \\ KM 14, Jalan Pantai, Si Rusa, Negeri Sembilan, MALAYSIA \\ ${ }^{2}$ Department of Mechanical Engineering, Faculty of Engineering, \\ Universiti Pertahanan Nasional Malaysia (UPNM) Kem Sg. Besi, Kuala Lumpur, MALAYSIA \\ akannan@polipd.edu.my, ${ }^{\mathrm{b}}$ saidynaidy@gmil.com \\ *Corresponding author. E-mail: saidynaidy@gmail.com, Tel: +6 017-2496293; Fax:+6038-946-7122
}

Keywords: Polypropylene, Rice Husk, treatment, sodium hydroxide, composite.

\begin{abstract}
There are many studies has been done on the natural fibers of cellulose contents as a reinforcing material. Yet, the main challenge in the research of natural fiber is the poor compatibility. In this study, the surface modification techniques were performed on granular size rice husk (RH) such as untreated, boiled and sodium hydroxide $(\mathrm{NaOH})$ treated reinforced polypropylene (PP) was consolidated to improve the mechanical properties. An internal mixer machine is set for four different composites compositions and the samples produced by hot press machine. The specimens were analyzed by different techniques such as hardness test, impact test, tensile test and scanning electron microscopy (SEM). This study shown that, the presence of $\mathrm{NaOH}$ indicates higher Young's modulus and hardness test value compared to boiled treated and untreated $\mathrm{RH}$. While for the impact strength and tensile strength value shows untreated, boiled treated and $\mathrm{NaOH}$ treated $\mathrm{PP} / \mathrm{RH}$ composite decreased when fiber loading increased. The morphological analysis was conducted to determine the effects of natural fiber bonding between the matrix materials after boiling and $\mathrm{NaOH}$ treatments for mechanical testing broken specimens.
\end{abstract}

\section{Introduction}

Polymer composite is a two or more material combination at the atomic level where the applications, such as in membranes, films, fibers, packaging, resins, biomedical, elastomers, emulsions, adhesives and coatings cannot be denied. The value added of composite materials is to replace synthetic fiber, such as carbon or glass fiber with natural fiber. In addition, the advantages of natural fiber composite are due to as non-abrasive to equipment, cost, biodegradability, high specific strength, abundancy, renewability, low specific gravity, nonabrasiveness, freedom from health problems due to skin irritation during conduct and processing $[1,2,3]$.

One of natural fibers with high availability is rice husk; a residue of the agricultural by product material. It constitutes about $20 \%$ of the weight of rice. It contains about $35 \%$ cellulose, $25 \%$ hemicellulose, $20 \%$ lignin, and $17 \%$ of ash (94\% silica) by weight $[4,5,6]$. Rice husk as pozzolan is an effective admixture for concrete and used as additives to reduce corrosion and increased durability of concrete structure [7]. Rice husk fine and rice husk coarse board showed outstanding properties in a ratio of cement and particles of 80:20 [8]. Thus, rice husk concrete can be successfully used as light weight concrete for the manufacture of structures where the weight of structure is of ultimate importance. [9]-[12].

The utilization of rice husk ash as a reinforcement of a polymeric material is provided several advantages, such as durability properties and improved strength, environmental benefits related to the disposal of waste materials and reduced materials costs, and to reduce carbon dioxide emissions [13]-[16]. The main issue of the using natural fiber composite is the fiber matrix adhesion. The hydrophilic natural fibers need to be treated properly in order to make them well-suited with hydrophobic thermosets or thermoplastics prior to processing of biocomposite. The occurrence of hydroxyl and other polar groups on the surface of the natural fiber may cause poor and weak bonding 
between fiber and matrix. There are a few chemical methods accessible which can advance the interfacial adhesion between the fiber and matrix [17]-[21]. The chemical and physical surface adaptation studies on a variety of natural fibers have been committed to understanding and enhancing the interface strength between the natural fibers and the polymer matrix. The tensile and impact strength decreased with rice husk loadings in the matrix, while the tensile modulus and hardness showed an opposite trend [22]. Habeeb and Fayyadh [23] study the effect of various size rice husk ash $(31.3,18.3$, and $11.5 \mu \mathrm{m})$. The results show that, the mechanical properties in terms of flexural and tensile strength has been significantly improved with the addition of rice husk ash, with the coarse rice husk ash showing the least improvement. When mixing the maleic anhydride grafted polyethylene in the interfacial adhesion between high density polyethylene and rice husk improve the flexural, tensile and impact strength. Scanning electron microscopy picture revealed some rice husk pulled out and numerous interfacial cavities occurred in the untreated high density polyethylene and rice husk composites [24]. It shows that presence of the compatibilizer significantly improved the interfacial adhesion. Ahmad et al [25] investigated the effects of filling rice husk and clay into high density polyethylene liquid natural rubber. Distribution of the filler in the composites showed the weak inter phase interaction in the composites.

Mustapa et al. [26] reported the effects of coupling agent and impact modifier on the mechanical properties of polypropylene rice husk composites. The results show that incorporation of $4 \mathrm{wt} \%$ of maleic anhydride grafted polypropylene in to the composite with $30 \mathrm{wt} \%$ of rice increased the flexural strength but decreased the flexural modulus and impact strength. While, Ethylene 1-octene copolymers is an effective impact modifier for polypropylene/ rice husk composite with significant improvement shown when $20 \%$ was incorporated into the composites. Besides that, according to Rosa et al. [27] the presence of maleic anhydride improved the tensile strengths while the composite stiffness was increase with increasing filler loading. Yang et al [28] determine the mechanical properties by using (10 to $40 \mathrm{wt} \%)$ rice husk flour as reinforcing fillers in the thermoplastic polymer composite. The results show tensile strengths of the composites slightly decreased as the filler loading increased but tensile modulus improved with increasing filler loading. Mean while, impact strengths were lowered by the addition of rice husk flour. Ismail et al. [29] investigated the rice husk ash filled natural rubber/linear low density polyethylene blends with and without a compatibilizer, polypropylene-ethylene-acrylic acid. The results show that, increasing rice husk ash loading in natural rubber/linear low density polyethylene blends resulted in reduction of tensile strength, but increased tensile modulus and hardness. Alaneme et al [30] investigated the mechanical behaviour of Al-Mg-Si alloy matrix composites reinforced with alumina $\left(\mathrm{Al}_{2} \mathrm{O}_{3}\right)$ and rice husk ash. The hardness of the hybrid composites decreases slightly with increase in rice husk ash for $3 \mathrm{wt} \%$ and $4 \mathrm{wt} \%$ rice husk ash containing hybrid composites. In addition, modify rice husk competent when imposed in thermoplastic composite.

However, the performance and properties of composite materials depend on the properties of the individual components and their interface compatibility. This study focused on the boiled and sodium hydroxide $\mathrm{NaOH}$ surface modification to improve the mechanical properties of the bio composite, while removing the lignin binder of the cellulosic material. The effects of the treatment on the fiber surface properties and on the mechanical properties of the biocomposites are presented in the following sections.

\section{Materials and methods}

\subsection{Material}

This research use Polypropylene as the matrix material in the form of pallet with a density 0.9 $\mathrm{g} / \mathrm{cm}^{3}$ and melting temperature at $230^{\circ} \mathrm{C}$ had been obtained for this research. This compound consists of carbon, hydrogen and some additives designed for general purpose applications (Figure 1). The rice husk fiber was obtained from the rice field Alor Star, Kedah, (Malaysia). Its moisture content is 13 wt. $\%$ where the granular sizes ranged are from 500 to $1000 \mu \mathrm{m}$. 

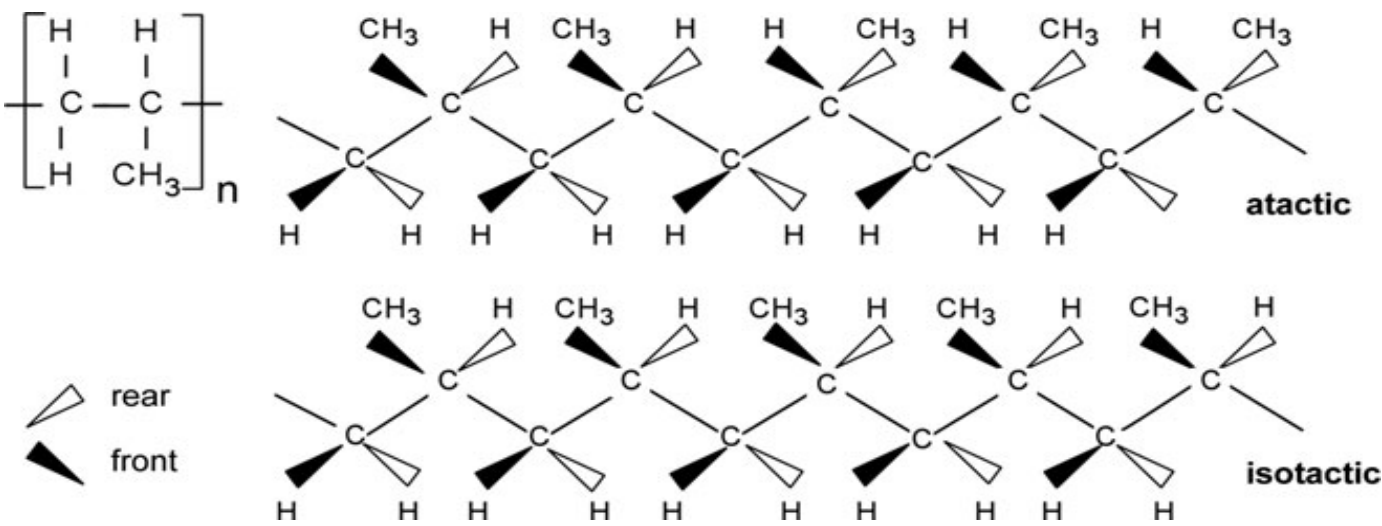

Figure 1: Tacticity (configuration) of the $\mathrm{CH}_{3}$ groups in polypropylene

\subsection{Materials preparation}

For untreated RH, the raw material was sun dried for three days. This process have to be carried out before they were fed into a blender in order to obtain short fibers at lower than $1000 \mu \mathrm{m}$ in length. While for the boiled and treated $\mathrm{RH}$, the preparation carried out is by washing process of the 120 grams of untreated RH and then it is boiled in the $100^{\circ} \mathrm{C}$ boiling water for about 1 hour. Thus, they are forwarded to soaking process for 2 hours with $2 \%$ concentration of Sodium Hydroxide $(\mathrm{NaOH})$ then the compound was stirred. The compound was left in the environmental chamber for 3 hours followed by cleaning process using normal pipe water. The washing process was repeated for 4 times to ensure no more $\mathrm{NaOH}$ residual at rice husk. The next process is drying the rice husk under sunlight for 24 hours, for three days. Figure 2 shows the different types of rice husk.

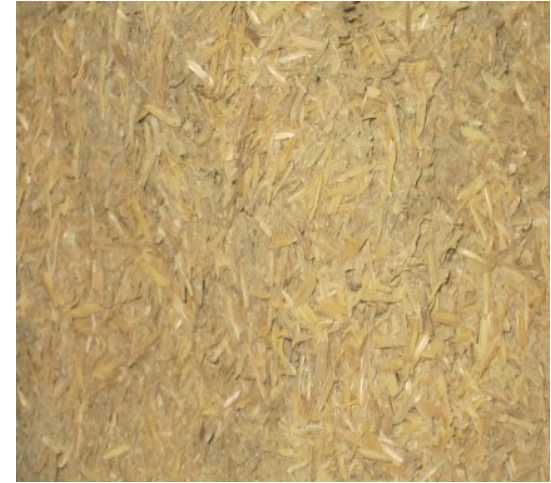

Pure RH

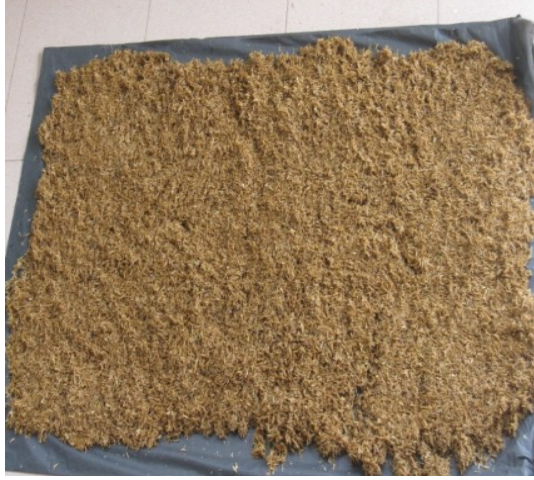

Boiled \& Treated RH

Figure 2: Different type of rice husk

\section{Fabrication of Composite}

The Polypropylene and rice husk is weighed according to selected ratio. A thermal mixing process was carried out using a Thermo Haake Rheomix 600 OS internal mixer at a temperature of $175{ }^{\circ} \mathrm{C}$ and a rotor speed of $50 \mathrm{rpm}$ for 10 minutes. Through this process, the mixture of substances will be found better and more uniform overall, after that the material goes to crusher machine to produce a standard particle size $2 \mathrm{~mm} \times 2 \mathrm{~mm}$. The final stage of the composite preparation process in this research is the hot pressing. Hot pressing was carried out at a temperature of $175{ }^{\circ} \mathrm{C}$ for 8 minutes, and the mixture was then cooled under room temperature. The final products were in the form of plates with dimensions of $200 \mathrm{~mm} \times 200 \mathrm{~mm} \times 2 \mathrm{~mm}$ and prepared to cut into ASTM standard and conduct mechanical testing.

\subsection{Tensile Test}

Sample cutter has been used to cut the sample in a dog bone shaped. Five samples of PP/RH composition untreated, boiled and treated with a dimension of samples $125 \mathrm{~mm} \times 12.7 \mathrm{~mm} \times 2 \mathrm{~mm}$ were tested according to ASTM standard D638. The tests were performed at $25 \pm 3^{\circ} \mathrm{C}$ with $50 \%$ of 
humidity and failure under tension at a crosshead speed of $5 \mathrm{~mm} / \mathrm{min}$ using Shimadzu Universal Testing Machine. Tensile strength and modulus were recorded. Here, the morphology of the cracked surface is observed by using scanning electron microscopy (SEM) at three types of magnifications that are $22 \mathrm{X}, 100 \mathrm{X}$ and $500 \mathrm{X}$, which consists of topographical, morphological and composition pictures.

\subsection{Hardness Test}

The hardness tests were performed according to ASTM E-384. The Micro Hardness Vickers is used to measure the depth of penetration of a loaded indented into the material. The tests were performed at $25 \pm 3^{\circ} \mathrm{C}$ with $50 \%$ of humidity. Average of night point has been taken from each composition.

\subsection{Impact Test}

The impact resistance test was carried out by using the "Pendulum Impact Tester Model: LS 22006-2" complete with hammer $25 \mathrm{~J}$ impact force and the operating conditions at $23 \pm 2{ }^{\circ} \mathrm{C}$ with $50 \%$ humidity. The test conducted in accordance with ASTM D6110 in order to determine the values of charpy impact strength $\left(\mathrm{J} / \mathrm{mm}^{2}\right)$. The five specimens were placed horizontally on a sample holder, and then will be broken by the swinging pendulum. Before the experiment, the width and thickness of the sample are measured by using the "digital vernier caliper" in which the average values are recorded.

\subsection{Morphological Observation of Fractured Surfaces through SEM}

Scanning Electron Microscope (SEM) observation was performed using Philips XL 30 ESEM operated at 20 to $30 \mathrm{kV}$. The fractured samples from the tensile test were first dried and coated with the gold using Sputter Coater Polaron E-5100 system. Dispersion state of rice husk fiber and the fracture mode of composites under the tensile loading were determined.

\section{Results and discussion}

In order to gain a clear understanding of the basic loading of granular size rice husk (RH) such as untreated, boiled and sodium hydroxide $(\mathrm{NaOH})$ treated, this section present the results of mechanical testing. Table 1 show the different percentage of various composition of rice husk.

Table 1: Different percentage of various composition of rice husk

\begin{tabular}{|c|c|c|c|c|c|c|c|c|c|}
\hline \multicolumn{2}{|c|}{ Composition } & \multicolumn{2}{|c|}{ Tensile } & \multicolumn{2}{|c|}{$\begin{array}{c}\text { Different of Percentage } \\
\%\end{array}$} & \multirow{2}{*}{$\begin{array}{l}\text { Hardness } \\
\text { (Hv) }\end{array}$} & \multirow{2}{*}{$\begin{array}{c}\text { Different } \\
\text { of \% }\end{array}$} & \multirow{2}{*}{$\begin{array}{l}\text { Impact } \\
\left(\mathrm{J} / \mathbf{m m}^{2}\right)\end{array}$} & \multirow{2}{*}{$\begin{array}{c}\text { Different } \\
\text { of \% }\end{array}$} \\
\hline PP & RH & $\begin{array}{c}\text { Strength } \\
(\mathrm{MPa})\end{array}$ & $\begin{array}{c}\text { Modulus } \\
(\mathrm{MPa})\end{array}$ & Strength & Modulus & & & & \\
\hline \multirow{3}{*}{90} & $10(\mathrm{U})$ & 10.02 & 810.0 & 0.000 & 0.000 & 9.2 & 0.000 & 1.95 & 0.000 \\
\hline & $10(\mathrm{~B})$ & 10.12 & 813.0 & 0.998 & 0.370 & 9.4 & 2.174 & 2.00 & 2.564 \\
\hline & $10(\mathrm{~T})$ & 10.41 & 820.0 & 3.892 & 1.235 & 10.0 & 8.696 & 2.20 & 12.821 \\
\hline \multirow{3}{*}{80} & $20(\mathrm{U})$ & 9.82 & 992.0 & 0.000 & 0.000 & 9.8 & 0.000 & 1.30 & 0.000 \\
\hline & $20(\mathrm{~B})$ & 10.01 & 995.0 & 1.935 & 0.302 & 10.1 & 3.061 & 1.45 & 15.000 \\
\hline & $20(\mathrm{~T})$ & 10.20 & 998.0 & 3.870 & 0.605 & 10.5 & 7.143 & 1.80 & 50.000 \\
\hline \multirow{3}{*}{70} & $30(\mathrm{U})$ & 9.15 & 1009.3 & 0.000 & 0.000 & 10.7 & 0.0 & 0.60 & 0.000 \\
\hline & $30(\mathrm{~B})$ & 9.35 & 1010.0 & 2.186 & 0.069 & 10.8 & 0.935 & 0.80 & 33.333 \\
\hline & $30(\mathrm{~T})$ & 9.75 & 1011.0 & 6.557 & 0.168 & 11.0 & 2.804 & 1.10 & 83.333 \\
\hline \multirow{3}{*}{60} & $40(\mathrm{U})$ & 8.35 & 1100.0 & 0.000 & 0.000 & 11.0 & 0.000 & 0.10 & 0.000 \\
\hline & $40(\mathrm{~B})$ & 8.85 & 1119.0 & 5.988 & 1.727 & 11.3 & 2.727 & 0.30 & 200 \\
\hline & $40(\mathrm{~T})$ & 9.32 & 1122.1 & 11.617 & 2.009 & 12.0 & 9.091 & 0.50 & 400 \\
\hline
\end{tabular}

Key: $\mathrm{U}=$ Untreated; $\mathrm{B}=$ Boiled \& $\mathrm{T}=$ Boiled \& $\mathrm{NaOH}$ Treated 


\subsection{Tensile Properties}

A tensile test was done to determine the strength and modulus of PP/RH composite, which was fabricated using the untreated, boiled and boiled $\& \mathrm{NaOH}$ treated fibers. Table 1 shows the complete tensile strength and percentage increase in strength for each composition. Figure 3 and 4 shows the effect of filler loading on tensile strength and tensile modulus. From the Figure 3, it can be seen that the tensile strength of PP/ RH decreased with increasing of rice husk. It happened because when filler loading increase the effective matrix cross section reduction and stress concentration increase. It is similar finding [12,13,14,15,16,17,18,19,20,21] where the less percentage of matrix cannot reinforced well with natural fiber and it make facture if stress is applied and easy to slip off. Although the boiled \& $\mathrm{NaOH}$ treated rice husk strength decreased when the percentage of rice husk composite increase but it is still improve when compared with untreated or boiled rice husk. It is possibility the $\mathrm{NaOH}$ can remove the amount percentage of hemicellulose, lignin and ash. The lowest tensile strength for the boiled \& $\mathrm{NaOH}$ treated rice husk composition is $9.32 \mathrm{MPa}$ with $11.617 \%$. The highest strength was achieved in the specimen that had been treated $10 \%$ rice husk composition. Mean while Figure 4 shows the tensile modulus of PP/ RH composite increased with increasing filler loading. The boiled \& $\mathrm{NaOH}$ treated rice husk composite can improve tensile modulus compared to boiling and untreated composite. The specimen made from PP/RH $(60 / 40)$ boiled \& NaOH treated shows the highest average modulus value $1122.1 \mathrm{MPa}$, with a $2.009 \%$ increase in strength. Similar results were reported by Ahmad et al [25] addition of rice husk and clay into the thermoplastic decrease the tensile strength but increase the modulus. The lowest average modulus PP/RH (90/10) boiled \& $\mathrm{NaOH}$ treated rice husk $820 \mathrm{MPa}$, which is a $1.235 \%$ increase in strength compare to untreated and boiled. While using rice husk flour in thermoplastic composite Yang et al [28] determine that tensile strengths of the composites slightly decreased as the filler loading increased but tensile modulus improved with increasing filler loading. Besides that, increasing the rice husk ash loading in natural rubber/linear low density polyethylene blends resulted in reduction of tensile strength, but increased tensile modulus [29]. The poor filler matrix interaction, resulting in weak filler distribution and large agglomerated particle size, caused those properties to decrease [22].

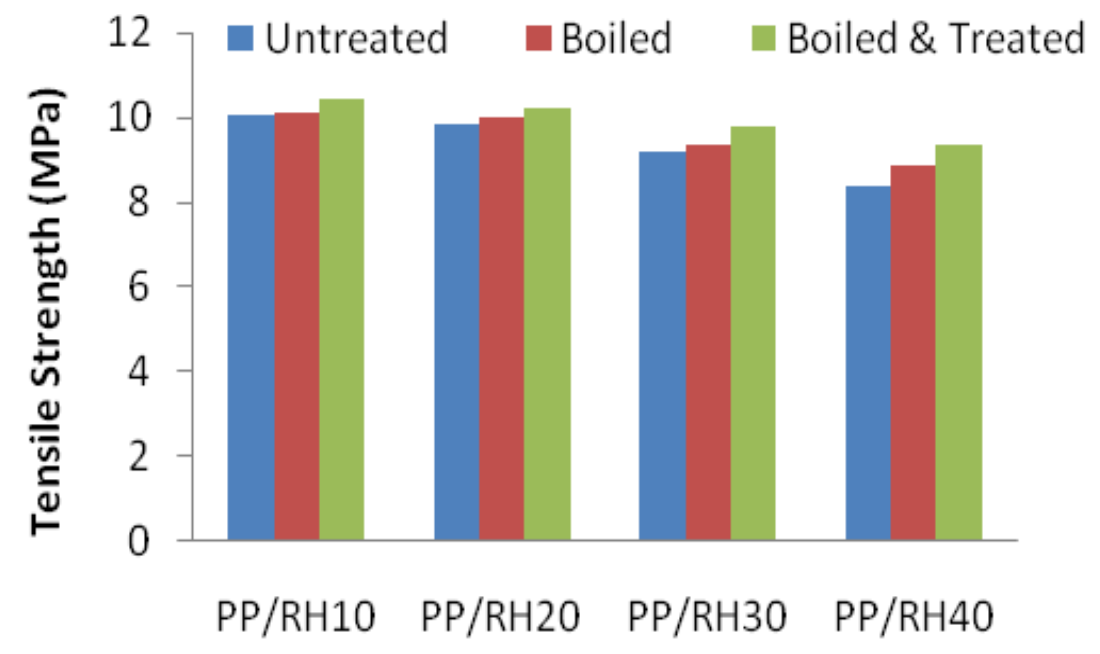

Blend Composition (wt \%)

Figure 3: Chart of Tensile Strength against percentage of Composition of PP \& RH 


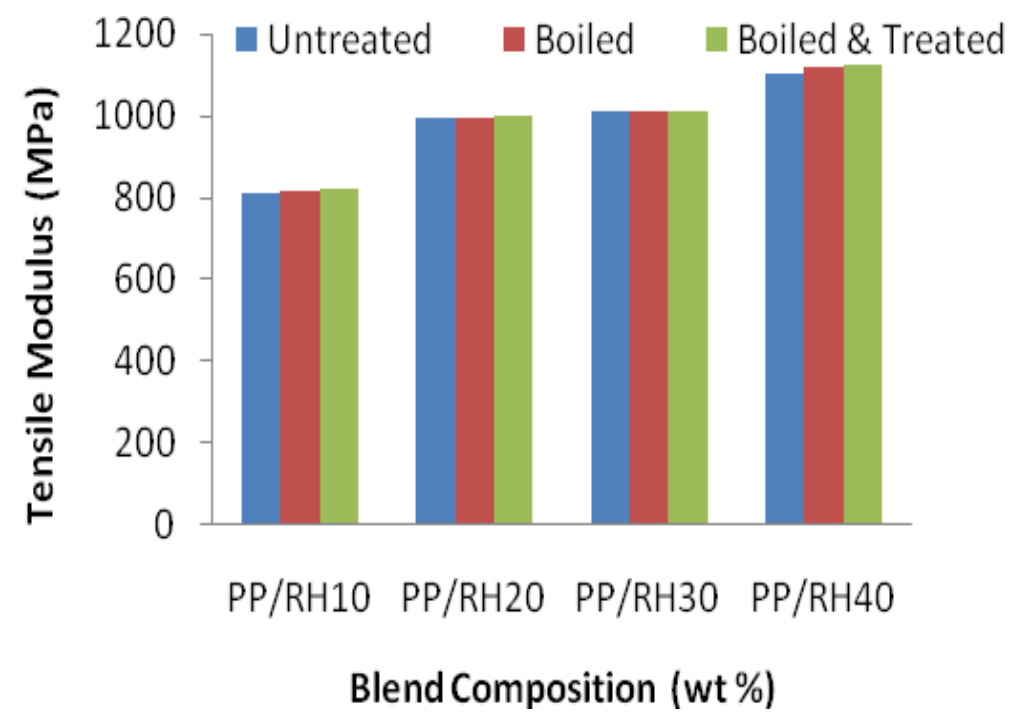

Figure 4: Chart of Tensile Modulus against percentage of Composition of PP \& RH

\subsection{Hardness Properties}

Table 1 shows the hardness value of the specimen made from untreated, boiled and boiled \& $\mathrm{NaOH}$ treated rice husk. Figure 5 demonstrates the effect of adding Sodium Hydroxide $(\mathrm{NaOH})$ on the hardness property of $\mathrm{PP} / \mathrm{RH}$ composite. It can be seen from the result obtained that hardness of boiled \& $\mathrm{NaOH}$ treated composite of $\mathrm{PP} / \mathrm{RH}$ is better than boiled or untreated composite. This result proved that reaction between boiling and treated rice husk with Sodium Hydroxide $(\mathrm{NaOH})$ in $\mathrm{PP} / \mathrm{RH}$ composition increases the stiffness property of composite. Similar results were reported by Ahmad et al [25] addition of rice husk and clay into the thermoplastic increase the hardness. The high hardness value of PP/RH (60/40) untreated composition is 11 and meanwhile the highest value for boiled \& $\mathrm{NaOH}$ treated with same composition is 12 values with $9.091 \%$ increment. Increasing rice husk ash loading in natural rubber/linear low density polyethylene increased hardness [29]. Generally, rice husk fibers that increase the value of composites increase the hardness of the thermoplastic [19]. The significant difference in the value shows that the percentage of RH composition will increase the hardness of the material as the bonding between the molecules. It is proved when the addition of the lower ratio of $\mathrm{NaOH}$ treated $\mathrm{RH}$ in to $\mathrm{PP} / \mathrm{RH}$ composition increases hardness value compared to boiling and untreated. In general, the results showed that the hardness of the composites is significantly enhanced with the addition of rice husk.

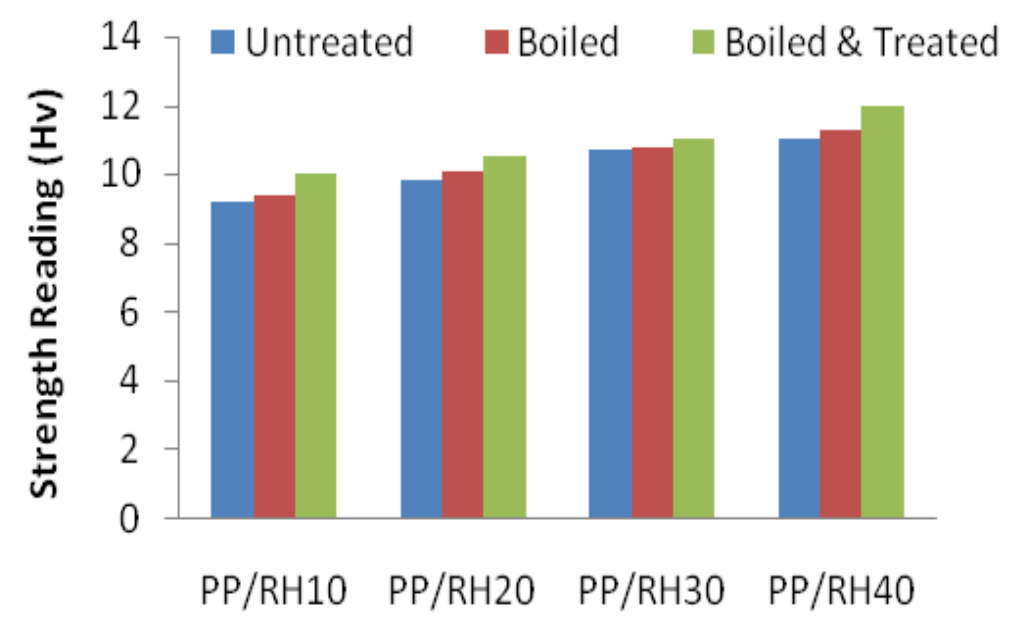

\section{Blend Composition (wt \%)}

Figure 5: Graph of Micro Vickers Strength against percentage Composition of PP \& RH 


\subsection{Impact Properties}

Table 1 show the complete impact strength and percentage increase in strength for each composition. Figure 6 demonstrates the effect of adding boiled and treated rice husk with Sodium Hydroxide on the impact property of $\mathrm{PP} / \mathrm{RH}$ composite. It can be seen from the result obtained that untreated, boiled and boiled $\& \mathrm{NaOH}$ treated composite of $\mathrm{PP} / \mathrm{RH}$ is decreased when fiber loading increased. The percentage different between $10 \%$ to $40 \%$ boiled \& $\mathrm{NaOH}$ treated rice husk is higher. It shows the less percentage of boiled $\& \mathrm{NaOH}$ treated rice husk is excellent properties. This result shows that reaction between Sodium Hydroxide $(\mathrm{NaOH})$ in higher percentage of rice decreases the impact strength. The weak filler matrix interaction resulting in poor filler dispersion and decrease the properties [22]. The highest impact value of $\mathrm{PP} / \mathrm{RH}(90 / 10)$ untreated composition is $1.95 \mathrm{~J} / \mathrm{mm}^{2}$ and meanwhile the highest value for boiled \& $\mathrm{NaOH}$ treated with same composition is $2.2 \mathrm{~J} / \mathrm{mm}^{2}$ with $12.821 \%$ increment. The lowest average impact strength $\mathrm{PP} / \mathrm{RH}(60 / 40)$ boiled $\& \mathrm{NaOH}$ treated rice husk $0.50 \mathrm{~J} / \mathrm{mm}^{2}$, with $400 \%$ and meanwhile the lowest value for same untreated composition is 0.1 $\mathrm{J} / \mathrm{mm}^{2}$. The similar trend is also observed by Yang et al [28] where the impact strengths were lowered by the addition of rice husk flour. The addition of rice husk and clay into the thermoplastic decrease the impact strength [25]. The addition of rice husk fiber composite generally decreased the impact value [18].

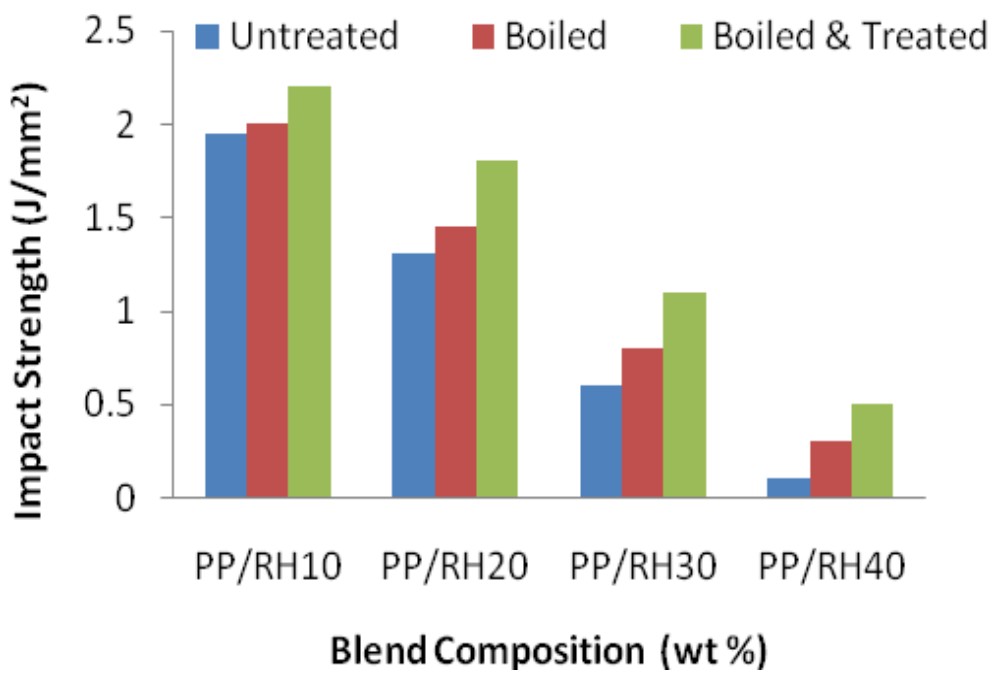

Figure 6: Graph of Impact strength against percentage Composition of PP \& RH

\subsection{Morphological Properties}

Alkali treatment reduces the lignin and hemicellulose content in natural fibers, increases the surface area, allowing dissemination of water molecules to the inner layers, and breaks the bonds between lignin-carbohydrate and hemicellulose [27]. In morphology properties, it can be seen that the effect of filler loading with the addition sodium hydroxide in the treated sample. This is outstanding to the fact that alkali treatment improves the fiber surface bond uniqueness by removing hemicelluloses and producing rough surface. This topography offers better fiber matrix interface bond and an increase in mechanical properties. Figure 7 shows the scanning electron microscope (SEM) sample analysis of pure rice husk. While Figure 8 and 9 shows the boiled and $\mathrm{NaOH}$ treated pure rice husk. From the SEM photos, the rice husk with boiled and $\mathrm{NaOH}$ treated fibers in Figure 10 look well contacted in the polypropylene matrix with PP/RH (60/40) composite adhesive characteristics, which proportional with the result of the tensile strength as shown in Figure 3. 


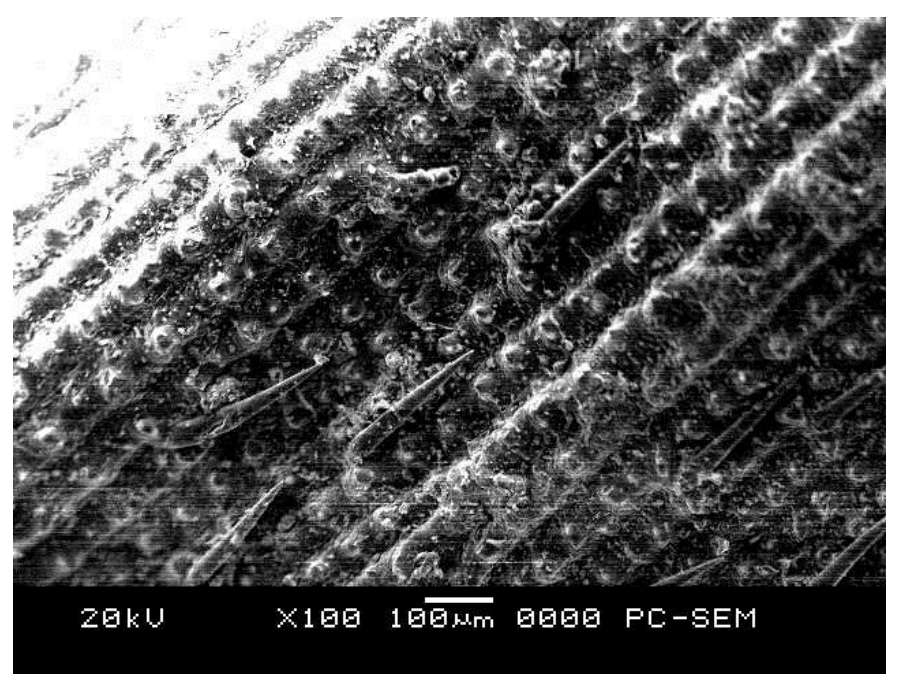

Figure 7: Magnification of Pure Rice Husk

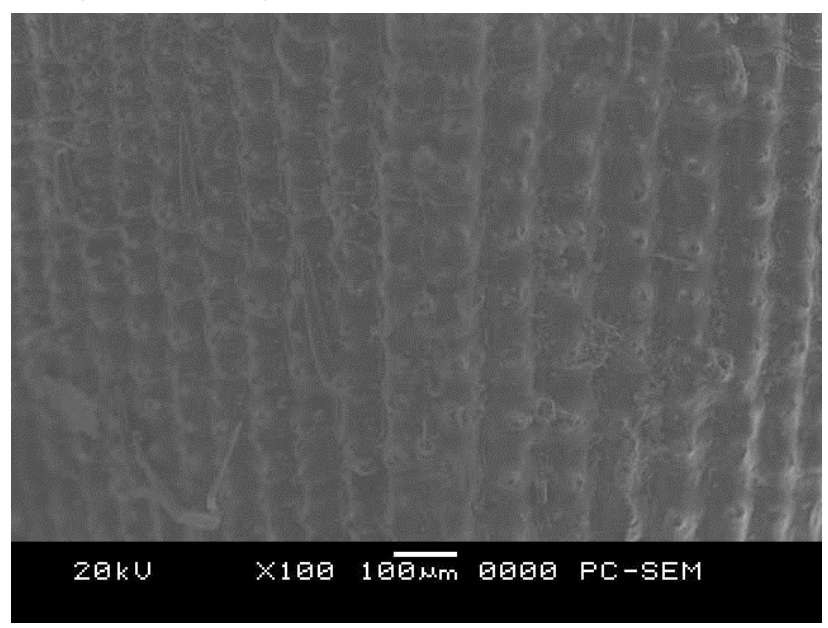

Figure 8: Magnification of Boiled Rice Husk

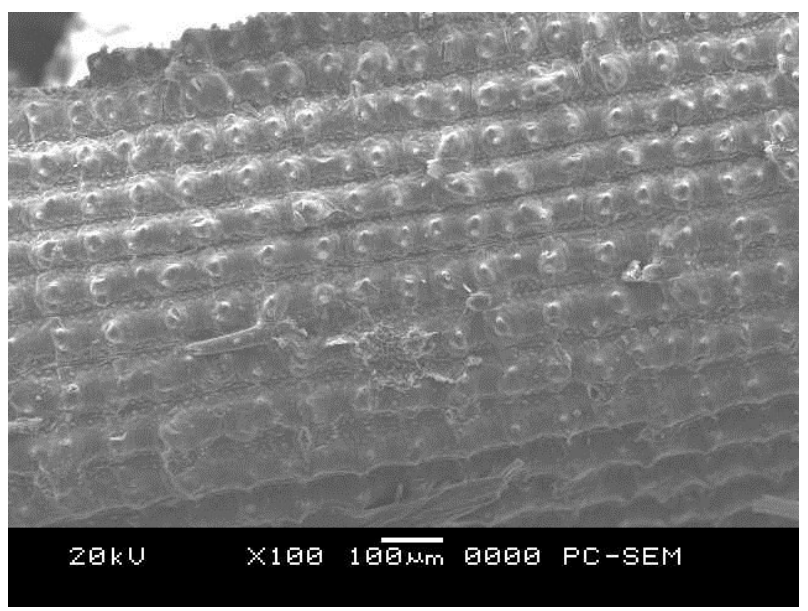

Figure 9: Magnification of Boiled and $\mathrm{NaOH}$ Treated Rice Husk 


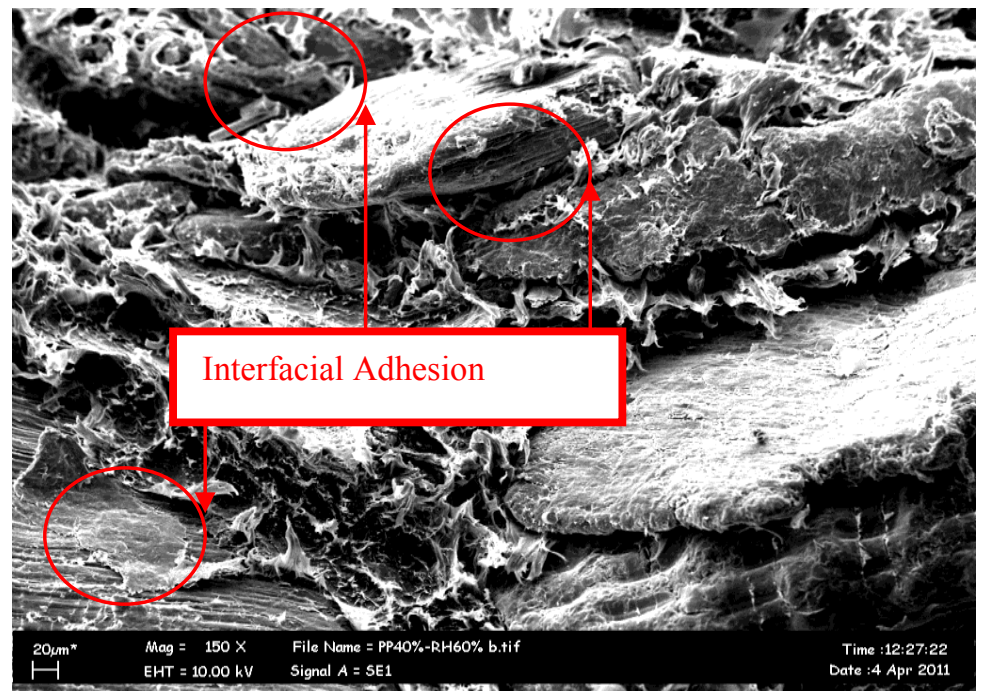

Figure 10: Magnification of Boiled and $\mathrm{NaOH}$ Treated Rice Husk at Mixture of $40 \mathrm{wt} \% \mathrm{PP} \& 60 \mathrm{wt}$. $\% \mathrm{RH}$

\section{Conclusions}

Based on the mechanical properties results, filling of boiled and boiled $\& \mathrm{NaOH}$ treated rice husk in a polypropylene matrix composite degrades the different rates of mechanical testing result. The presence of boiled and boiled \& $\mathrm{NaOH}$ treated $\mathrm{RH}$ increases the effective of tensile modulus and hardness value result between fiber and matrix. While for tensile strength and impact strength both treated and untreated RH loading decreased the composite properties. The result showed that the boiled \& $\mathrm{NaOH}$ treated rice husk exhibited the highest tensile strength $10.41 \mathrm{MPa}$ (PP 90/RH 10), tensile modulus 1122.1 MPa (PP 60/RH 40), hardness 12.0 (PP 60/RH 40) and Impact strength 2.20 $\mathrm{J} / \mathrm{mm}^{2}$ (PP 90/RH 10). It shown that the presence of boiled and sodium hydroxide $\mathrm{NaOH}$ rice husk indicates superior properties when compared to boiled treated and untreated rice husk.

\section{Acknowledgments}

The authors acknowledge to Polytechnic Port Dickson and Universiti Pertahanan National Malaysia (UPNM) for supporting the research work, as well as The Coordinator of Composite Engineering Laboratory (FKP/UTEM) for granting permission to use all available equipments.

\section{References}

[1] M.A. Maleque, A. Atiqah, Development and characterization of coir fibre reinforced composite brake friction materials, Arabian Journal for Science and Engineering. 38(11) (2013) 3191-3199.

[2] K. Rassiah, M.M.H Megat Ahmad, Bamboo, thermoplastic, thermosets, and their composites: a Review, Appl Mech Mater. 330 (2013) 53-61.

[3] K. Rassiah, M.M.H Megat Ahmad, Aidy Ali, Mechanical Properties of Laminated Bamboo Strips From Gigantochloa Scortechinii / Polyester Composite, Materials and Design. .57 (2014) 551-559.

[4] S. Panthapulakkal, M. Sain, S. Law, Effect of Coupling Agents on Rice Husk Filled HDPE Extruded Profiles, Polymer International. 54(1) (2005) 137-142.

[5] A.A. Ramezanianpour, M. Mahdikhani, Gh. Ahmadibeni, The Effect of Rice Husk Ash on Mechanical Properties and Durability of Sustainable Concretes, International Journal of Civil Engineering. 7(2) (2009) 83-91.

[6] G.A. Akeke, M.E. Ephraim, I.Z.S. Akobo, J.O. Ukpata, Structural Properties of Rice Husk Ash Concrete, International Journal of Engineering. 3(3) (2013) 57-62. 
[7] T.U. Ganiron Jr, Effects of Rice Hush as Substitute for Fine Aggregate in Concrete Mixture, International Journal of Advanced Science and Technology. 58 (2013) 29-40.

[8] M. Sarkar, M. Asaduzzaman, A.L. Das, M.O. Hannan, M.I. Shams, "Mechanical Properties and Dimensional Stability of Cement Bonded Particleboard from Rice Husk and Sawdust, Bangladesh Journal of Scientific and Industrial Research. 47(3) (2012) 273-278.

[9] S.D. Nagrale, H. Hajare, P.R. Modak, Utilization of Rice Husk Ash, International Journal of Engineering Research and Applications. 2(4) (2012) 1-5.

[10] S. Demis, J. G. Tapali, V. G. Papadakis, Plant Design and Economics of Rice Husk Ash Exploitation as a Pozzolanic Material, Waste and Biomass Valorization. 6(5) (2015) 843-853.

[11] S.H. Sathawane, V.S. Vairagade, K.S Kene, Combine Effect of Rice Husk Ash and Fly Ash on Concrete by 30\% Cement Replacement, Procedia Engineering. 51 (2013) 35-44.

[12] A.K. Parande et al., Utilization of Agroresidual Waste in Effective Blending in Portland Cement, Civil Engineering. (2011) 1-12.

[13] A. A. Yussuf, I. Massoumi, A. Hassan, Comparison of Polylactic Acid/Kenaf and Polylactic Acid/Rise Husk Composites: The Influence of the Natural Fibers on the Mechanical, Thermal and Biodegradability Properties, Journal of Polymers and the Environment. 18 (2010) 422-429.

[14] K. Rassiah, P. Balakrishnan, Studies on Biodegradability of Rice Husk/ E-Glass/Polypropylene Hybrid Composites, Journal of Global Engineers and Technologists Review. 4(3) (2014) 1-5.

[15] K. Rassiah, P. Balakrishnan, M.A. Asrudin, Effect of Sodium Hydroxide on the Biodegradability Studies of Rice Husk/E-Glass/Polypropylene Hybrid Composites, Malaysia Polymer International Conference, 2013.

[16] K. Rassiah, P. Balakrishnan, M. Nazarudin, Improving Mechanical Properties of Rice Husk/ Polypropylene Composites Using Sodium Hydroxide, National Conference on Engineering Technology. 1(2) (2013) 229-234.

[17] R. Santiagoo, H. Ismail, K. Hussin, Mechanical Properties, Water Absorption, and Swelling Behaviour of Rice Husk Powder Filled Polypropylene/ Recycled Acrylonitrile Butadiene Rubber (PP/NBRr/ RHP) Biocomposites Using Silane as a Coupling Agent, Peer-Reviewed Bio Resourced. 6 (4) (2011) 3717-3726.

[18] M.R. Nouri et al., Mechanical Properties and Water Absorption Behaviour of Chopped Rice Husk Filled Polypropylene Composites, Iranian Polymer Journal. 15(9) (2006) 757-766.

[19] N.A. Maziad, D.E. EL Nashar, E. M. Sadek, The Effects of a Silane Coupling Agent on Properties of Rice Husk-Filled Maleic Acid Anhydride Compatibilized Natural Rubber/Low-Density Polyethylene Blend, Journal of Material Science. 44(10) (2009) 2665-2673.

[20] V. Ramasamy, Compressive Strength and Durability Properties of Rice Husk Ash Concrete, Journal of Civil Engineering. 16(1) (2012) 93-102.

[21] K. Ahmed et al., An Assessment of Rice Husk Ash Modified, Marble Sludge Loaded Natural Rubber Hybrid Composites, Journal of Materials and Environmental Science. 4(2) (2013) 205-216.

[22] M.S. Jamil, I. Ahmad, I. Abdullah, Effects of Rice Husk Filler on the Mechanical and Thermal Properties of Liquid Natural Rubber Compatibilized High-Density Polyethylene/Natural Rubber Blends, Journal of Polymer Research. 13(4) (2006) 315-321.

[23] G.A. Habeeb, M. M. Fayyadh, Rice Husk Ash Concrete: The Effect of RHA Average Particle Size on Mechanical Properties and Drying Shrinkage, Australian Journal of Basic and Applied Sciences. 3(3) (2009) 1616-1622.

[24] N. Petchwattana, S. Covavisaruch, S. Chanakul, Mechanical Properties, Thermal Degradation and Natural Weathering of High Density Polyethylene/Rice Hull Composites Compatibilized with Maleic Anhydride Grafted Polyethylene, Journal of Polymer Research. 19(7) (2012) 1-9. 
[25] I. Ahmad, M.S.M. Jamil, I. Abdullah, Pengisian Sekám Padi dan Tanah Liât ke Dalam Matriks Polietilena Berketumpatan Tinggi-Getah Asli-Getah Asii Cecair, Sains Malaysiana. 38(3) (2009) 381-386.

[26] M. Mustapa, Azman Hassan, A. Rahmat, Preliminary Study on the Mechanical Properties of Polypropylene Rice Husk Composites, Symposium Polimer Kebangsaan. (2005) 23-24.

[27] S.M.L. Rosa et al., Studies on the Properties of Rice-Husk-Filled-PP Composites: Effect of Maleated PP, Materials Research. 12(3) (2009) 333-338.

[28] H.S.Yang et al., Rice-Husk Flour Filled Polypropylene Composites; Mechanical and Morphological Study, Composite Structures. 63(3) (2004) 305-312.

[29] H. Ismail, J. M. Nizam, H.P.S. Abdul Khalil, The Effect of a Compatibilizer on the Mechanical Properties and Mass Swell of White Rice Husk Ash Filled Natural Rubber/Linear Low Density Polyethylene Blends, Polymer Testing. 20(2) (2001)125-133.

[30] K.K. Alaneme et al., Fabrication Characteristics and Mechanical Behaviour of Rice Husk Ash-Alumina Reinforced Al-Mg-Si alloy Matrix Hybrid Composites, Journal of materials research and technology. 2(1) (2013) 60-67. 